\title{
Understanding farmers' reluctance to reduce pesticide use: A choice experiment
}

\author{
Benoît Chèze $^{\mathrm{a}, \mathrm{b}, \mathrm{c}}$, Maia David ${ }^{\mathrm{a}}$, and Vincent Martinet ${ }^{\mathrm{a}, \mathrm{c}}$ \\ ${ }^{\mathrm{a}}$ Economie Publique, AgroParisTech, INRA, Université Paris Saclay, F-78850, \\ Thiverval-Grignon, France. \\ bIFP Énergies Nouvelles, 1-4 av. de Bois Préau, F-92852 Rueil-Malmaison, France. \\ ${ }^{\mathrm{c}}$ EconomiX-CNRS, University Paris Nanterre, France. \\ Emails benoit.cheze@ifpen.fr maia.david@agroparistech.fr vincent.martinet@inra.fr
}

June 19, 2019

\begin{abstract}
Despite reducing the use of pesticides being a major challenge in developed countries, dedicated agri-environmental policies have not yet proven successful in doing so. We analyze conventional farmers' willingness to reduce their use of synthetic pesticides. To do so, we conduct a discrete choice experiment that includes the risk of large production losses due to pests. Our results indicate that this risk strongly limits farmers' willingness to change their practices, regardless of the consequences on average profit. Furthermore, the administrative burden has a significant effect on farmers' decisions. Reducing the negative health and environmental impacts of pesticides is a significant motivator only when respondents believe that pesticides affect the environment. Farmers who earn revenue from outside their farms and/or believe that yields can be maintained while reducing the use of pesticides are significantly more willing to adopt low-pesticide practices. Policy recommendations are derived from our results.
\end{abstract}

Keywords: Pesticides; Agricultural practices; Production risk; Discrete choice experiment

JEL Classification: Q12, Q18, Q51, Q57, C35 


\section{Introduction}

Reducing the use of synthetic pesticides in agriculture has become a major challenge in developed countries. As shown by the recent extremely rapid growth in organic farming $(+20 \%$ of sales in France in 2016; AgenceBio, 2017), consumers are becoming increasingly aware of this issue (refer to Bernard and Bernard, 2010, on the link between organic sales and public concern about pesticides).

Public policies over the last 10 years have attempted to provide adequate incentives to change behavior and boost research related to this topic. European Union member states are required to implement National Action Plans that set quantitative objectives, timetables, and indicators related to reducing the impact of pesticide use (Directive 2009/128/CE). Several member states have also developed voluntary schemes that offer financial support to farmers to reduce their use of pesticides and/or convert to organic farming (e.g., Denmark, France, Germany, Spain, the Netherlands, the United Kingdom). The United States, Canada, Australia, the European Union, Iceland, and Norway have developed programs to monitor pesticide residues in food, as well as awareness campaigns. However, thus far, the results of these policies have been disappointing. The use of chemical inputs by farmers has increased, for example, in Europe during the last decade $(+12 \%$ in France between the three-year mean for the period 2009-2011 and that for the period 2012-2014; Ecophyto, 2015), along with a lack of participation in agri-environmental schemes on pesticides (Thoyer et al., 2015).

Several agricultural practices have now proven efficient in maintaining satisfactory yields, while reducing the use of chemicals (Lechenet et al., 2017). Reducing pesticides may reduce farmers' costs, improve their health and environment, and prevent pest resistance (Wilson and Tisdell, 2001; Bourguet and Guillemaud, 2016). What are the main obstacles preventing farmers from adopting low-pesticide practices, which could be win-win strategies in some cases? Researchers in ecology and agronomy, as well as public decision-makers (Solomon, 2015; Rousset et al., 2012), are looking to economists for a better understanding of the socioeconomic factors that explain farmers' behavior.

Our study contributes to the literature by measuring the relative weights of various factors that influence the choice of conventional farmers to reduce - or not - their use of synthetic pesticides. Several socioeconomic analyses have examined the motivations and obstacles to the adoption of environmentally friendly practices by farmers. The methodologies employed by such studies include focus groups, qualitative surveys, role-playing games, and agent-based models 11 In contrast to these useful and complementary methodologies, we adopt a quantitative

${ }_{1}^{1}$ Dumont et al. (2016); Malawska and Topping (2016); Greiner et al. (2009); Wilson and Tisdell (2001); Knowler and Bradshaw (2007). 
approach to estimate the weight of each decision factor, as well as farmers' willingness to pay (WTP) for/willingness to accept (WTA) changes in these factors. Our methodology is based on a nonmarket valuation, using a discrete choice experiment (DCE).

The DCE method has gained popularity among environmental economists during the last 10 years. This stated preference method elicits preferences through repeated fictional choices among different options, each defined by their attributes, i.e., fundamental characteristics of the respondent's situation in that option (Hoyos, 2010, Louviere et al., 2000). While other nonmarket valuation methods (e.g., contingent valuation) can account for several characteristics in the description of the scenarios to be valued, DCEs are specifically designed to assess the WTP/WTA for each attribute that describes the choice options. As a result, the DCE approach is useful for valuations of agri-environmental policies, for two main reasons. First, it defines the relative importance of each consequence of reducing pesticide use on farmers' decisions. As such, the DCE approach can help in setting priorities for public action by identifying the most important factors for farmers, as well as the trade-offs at stake. This is key to identifying why a public program is unsuccessful or successful. Second, it enables a monetary valuation of the main consequences of pesticide reduction, which helps to set policies at the right level (e.g., set adequate subsidies).

The DCE approach has been used previously to examine farmers' choices in adopting environmentally friendly practices. Depending on the studies, the adoption of the alternative practice can occur within ${ }^{2}$ or independently of ${ }^{3}$ agrienvironmental contracts with public authorities. To the best of our knowledge, only a few DCEs have studied the specific issue of pesticide reduction. Blazy et al. (2011) examine the willingness to adopt agro-ecological innovations, in particular, to reduce pesticide use, while maintaining a sufficient yield. Christensen et al. (2011) analyze the motivations of Danish farmers in signing subsidy schemes for pesticide-free buffer zones. They show that contract flexibility is a major decision criterion. Kuhfuss et al. (2014) examine the decision of French wine growers to sign an Agri-Environmental Scheme, in which the payment is partly individual and partly based on a collective result (i.e., there is a bonus payment if the number of participants is above a given threshold). They show that farmers place significant value on the collective component of the contract. Jaeck and Lifran (2014) study the choice of rice-growers in Camargue (France) to reduce their use of chemical inputs, showing that targeted contracts are necessary, owing to the heterogeneity of farmers. Interestingly, they introduce production risk as an attribute of their

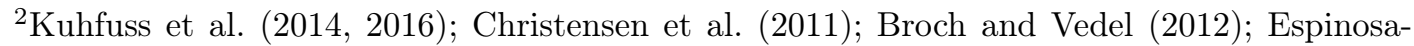
Goded et al. (2010); Ruto and Garrod (2009); Hudson and Lusk (2004); Peterson et al. (2015). (2015). 


\footnotetext{
${ }^{4}$ The literature distinguishes between risk (events with known probabilities) and uncertainty (events with unknown probabilities). In our literature review, we retain the term employed by individual studies, even when the authors acknowledge that they have used it loosely. In the remainder of this paper, we use the term risk, because we rely on the frequency of bad events to describe the variability of outcomes.

${ }^{5}$ Other methodological approaches have been used to investigate how risk affects farmers' choices, particularly those related to applying risk-reducing inputs (see, e.g., Roosen and Hennessy, 2003, Just and Pope, 2003, Liu and Huang, 2013, and the references therein).
} 
Subsections 4.1 and 4.2 present the results for the RPL model. We present the WTP/WTA estimates in Subsection 4.3. Lastly, Section 5 contains the conclusions, discussion, and policy implications of our results.

\section{The choice experiment}

The discrete choice experiment (DCE) approach relies on the economic theory of consumer choice and nonmarket valuation. In a DCE survey, respondents must choose from several options, defined by their attributes (i.e., fundamental characteristics of a respondent's situation). Often, three options are presented: nothing changes (i.e., the status quo), and two alternative options. The use of an optout option (status quo) is known to improve realism in choices (Adamowicz and Boxall, 2001, Kontoleon and Yabe, 2003). Respondents then choose their favorite option. Each option has different levels of the attributes. One of these attributes usually represents the monetary contribution of the respondents. Other attributes can include environmental or social implications of the issue under consideration. See Louviere et al. (2000) for a detailed description of the method.

By varying the level of the different attributes of options, the DCE framework delivers more information on the trade-offs between the drivers of choice than other stated preference methods do. In particular, it makes it possible to estimate the marginal rates of substitution between different attributes. When one attribute is expressed in monetary terms, these marginal rates of substitution can be interpreted as the WTA or WTP for changes in the attributes' values.

In our case, the respondents are farmers who choose between conserving their current agricultural practices (status quo) and adopting alternative practices that reduce their use of pesticides. The attributes of the alternatives represent the consequences of changes in agricultural practices. These changes are unspecified, and could refer to any modification reducing the use of pesticides. We chose not to be explicit on the description of the exact nature of these changes in order to avoid being inappropriate to certain farmers' specific situations. However, we used precise and diversified examples to make the options concrete for different types of respondents (see Appendix A.1 for examples).

\subsection{Choice of attributes and their levels}

The first step in our study was to choose the attributes and their associated levels. The reduction of pesticide use by farmers can have many drivers and consequences, depending on context, e.g., if this reduction is associated with the adoption of agroecological practices, the conversion to organic farming, or the participation in an agri-environmental scheme. Such a change can result in monetary gains due 
to a reduction of input costs, an increased sales price, or subsidies. It can produce non-monetary outcomes, such as the improvement of farmers' public image, participation in a network, the improvement of farmers' quality of life and health, and improved quality of the environment. It can also have negative outcomes, such as reduced yields, increased risk, the necessity to train to learn new agricultural techniques.

As Hanley et al. (2002) explains, the number of attributes considered in a DCE must be limited in order to avoid the cognitive burden of making choices that are too complicated. The selection of the attributes was based on (i) the literature, (ii) discussions with experts in agronomy, epidemiology, ecology, and agricultural economics, (iii) focus groups of farmers, ${ }^{6}$, and (iv) pretests on the choice sets. $]^{7}$ The focus groups and pretests revealed that pesticides are a sensitive topic among the French farming community; thus, we were careful with the employed terms and their potential interpretations. We were also careful to choose attributes that are adapted to different types of farming systems, while remaining concrete for farmers.

As shown in Table 1, the chosen attributes are as follows:

1. The farmer's yearly profit (or gross margin) per hectare, expressed in comparison with the status quo. This average profit per hectare per year, in euro, is the monetary (or cost) attribute. The profit varies with changes in agricultural practice, owing to unspecified factors such as the impact on yields, pesticide expenses, public aid (e.g., subsidies), sales price, and so on. Therefore, the farmer's profit can increase or decrease with a reduction of pesticides. Following our discussions with experts and the focus groups, this attribute was given the following possible values: $-50 €,+0 €,+50 €,+100 €$.

2. The production risk, formalized as the frequency of years (number of years out of 10) in which production is drastically and exceptionally reduced owing to pests (i.e., more than $30 \%$ of production is lost or damaged owing to diseases, insects, weeds, and so on). This attribute characterizes the main effect of the reduction of pesticides on the variability of production, independently of the level of production or profit (the mean yearly profit is given by the previous attribute). The production risk attribute is expressed in additional

\footnotetext{
${ }^{6}$ The focus groups included farmers who were supervising AgroParisTech students for internships on farms. Eight farmers, including field crop farmers, mixed crop/livestock farmers, and vegetable farmers, answered open questions on our topic.

${ }^{7}$ The pretests consisted of five face-to-face interviews with farmers on a preliminary version of the questionnaire. Additional pretests were done on five individuals of the general population (nonfarmers) to test the readability and consistency of various versions of the questionnaire. These pretests led to several modifications, in particular, the wording of attributes, as explained below.
} 
years out of $10(+0,+1$ year, or +2 years $)$, compared with the status quo. These levels were set after discussions with experts (farmers, agronomists, and epidemiologists).

3. The administrative framework of the change in practice describes whether the change accompanies an administrative commitment. A change of agricultural practices inducing a reduction in pesticide use may be included as part of an administrative framework. Such a framework can be perceived positively, because it may imply better-valued products, or integration in a network; however, it may also include an administrative burden and, thus, be perceived negatively. This attribute is qualitative, and is expressed as additional commitment over and above the status quo, as follows: "No additional administrative commitment," "charter" (inducing no contractual specification and flexible commitment), "agri-environmental contract with public authorities" (with specification, and possibly a subsidy), and a "certification process" (with a specification, controls, and a green label, possibly inducing higher sales prices). The potential subsidy or higher sales prices are included in the level of profit given in the first attribute. Only non-monetary aspects of the administrative commitment are included in the administrative commitment attribute.

4. The health and environmental impacts indicate the reduction in exposure to harmful substances as a result of the change in practice. This includes the local and global environmental quality (biodiversity, water quality) and the health of farmers, neighbors, and general population. This attribute takes the following values: $-0 \%$ (status quo only), $-20 \%,-50 \%-80 \%$, compared with the status quo.

Adding an attribute to encompass production risk helps to increase the credibility of valuation scenarios and reduces hypothetical bias (Rolfe and Windle. 2015). However, the concept of risk is difficult to express as an attribute in a way that is convenient and understandable to respondents. Whereas a mean value expressed as an average is easy to understand by respondents, other scientific terms used to describe a probability distribution, such as variance or standard deviation (or worse, skewness and kurtosis), are poorly understood by the public. Jaeck and Lifran (2014) expressed their risk attribute as the frequency of below-average yields (zero, one, or three years over five years). This formulation is clear, but it does not allow us to convey the idea of a risk of large production loss due to pests.$^{8}$ We wanted to capture the idea that pesticide reduction may induce a

${ }^{8}$ Having "zero years" of below-average yield implies no risk at all (i.e., the average yield is a sure outcome). Having "one year" of below-average yield conveys no information on the 


\begin{tabular}{lll}
\hline Attribute & Description & Levels \\
\hline Profit & Variation in the average & $-50 € ;+0 €(\mathrm{SQ}) ;$ \\
& yearly profit per hectare & $+50 € ;+100 €$ \\
\hline Production risk & Variation in the number of years, & +0 year (SQ); \\
& out of 10 years, with exceptionally & +1 year; \\
& large production losses & +2 years \\
\hline Administrative & Administrative framework of the change & None (SQ); Charter; \\
commitment & of practice, if any & Contract; Certification \\
\hline Health and & Reduction in exposure to & $-0 \%($ only SQ); \\
environmental impacts & harmful substances & $-20 \% ;-50 \% ;-80 \%$ \\
\hline
\end{tabular}

SQ: level in the status quo (also possible in the other options)

only SQ: level only possible in the status quo option

Table 1: Attributes and levels

larger variability of production, along with an increase in the occurrence of pest attacks resulting in exceptionally large production losses. Discussion within the focus groups confirmed that this was a realistic outcome in the event of low or no pesticide use. We thus opted for the frequency of years with large damages and production losses, for a given mean profit (given by the first attribute). Our production risk attribute is related to the variability of the losses due to pests, but not to the mean yield or mean profit. Consequently, the profit attribute and the risk attribute are independent. Various tests show that the proposed formulation offers an easy way to express production variability due to an increase of extreme losses.

For the "health and environmental impacts" attribute, we first considered having two separate attributes for health and for the environment. We finally chose to group them, because both are highly correlated (Juraske et al., 2007) and we were limited in the number of attributes. In addition, we initially wanted to express this attribute as a reduction of the treatment frequency index (TFI), a crop- and regionnormalized indicator of pesticide use, widely used and understood by European farmers. However, pretests revealed that this formulation induced misinterpretations and acceptability problems from farmers who perceived it as a technical objective to be achieved. Whenever farmers believe that achieving the proposed reduction is not possible for their farms, they opt for the status quo. Because we wanted to value here the environmental and health impacts of the agricultural

magnitude of the risk. Having "three years" of below-average yield implies an asymmetry of the yield distribution, with smaller deviations from the average for the more frequent losses than for the less frequent gains (possibly a positive skew). It is the opposite effect we want to convey (increase in the probability of very large losses). 

opted for this formulation.
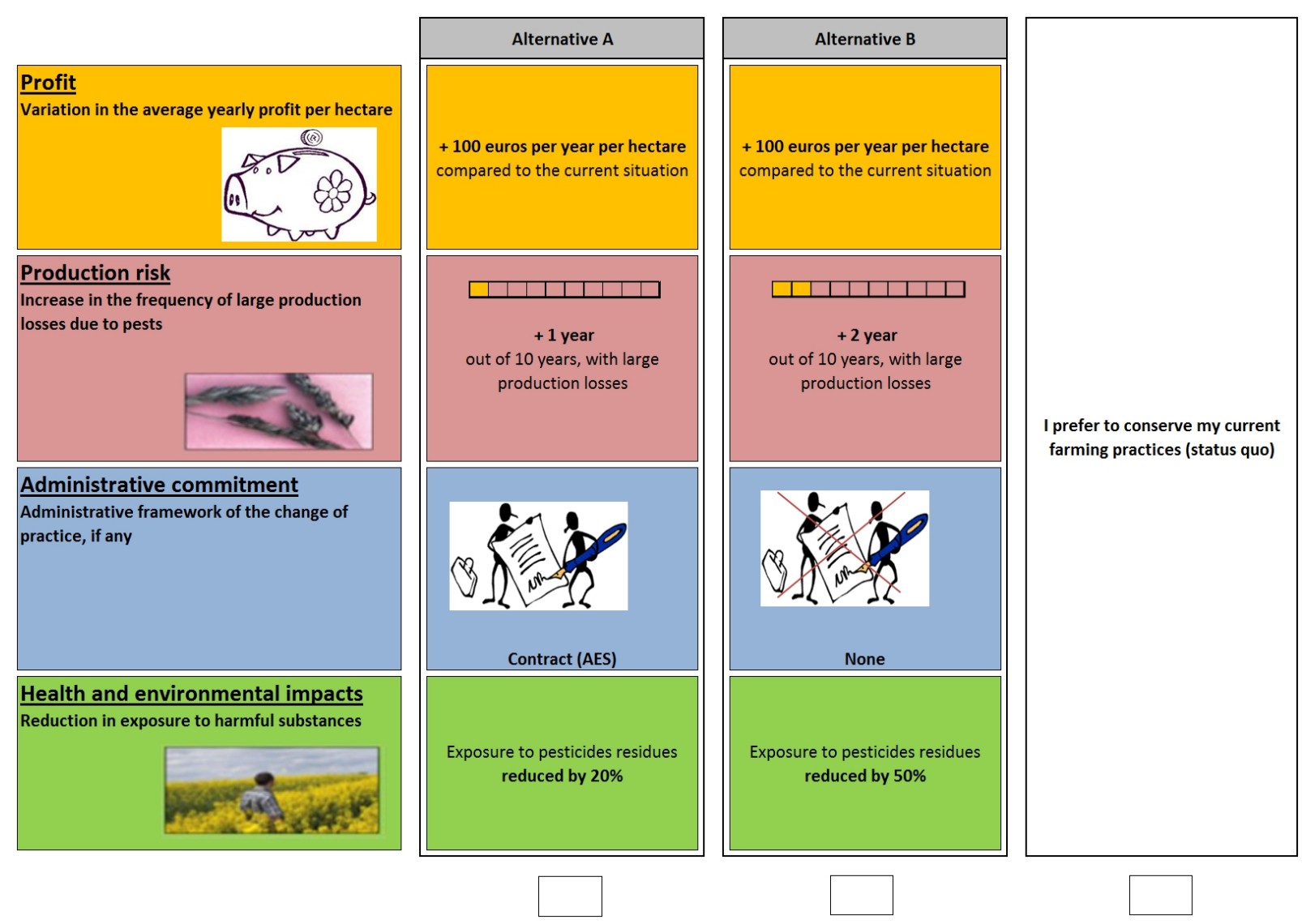

practice, rather than the constraints it implies (captured by other attributes), we

Figure 1 shows an example of a choice set, where the first column gives the attribute's title and short definition, the three following columns represent three options from which the respondent must choose (the last one being the status quo).

Figure 1: Example of a choice set (translated from French)

\subsection{Experimental design}

The aim of the experimental design is to construct the choice sets (i.e., combinations of attribute levels) that are presented to respondents. With four attributes and three to four levels each, the questionnaire would be far too heavy if all possible combinations of attribute levels were submitted to respondents. To choose the most relevant choice sets, which are those yielding maximum information on respondents' preferences, we used experimental design techniques (see Louviere et al. 2000, Street et al., 2005) and a dedicated software package (Ngene), which 


\footnotetext{
${ }^{9}$ Details of the efficient design used, and the associated program are available upon request.

${ }^{10}$ Using mixed-mode surveys is an efficient and satisfactory method to increase the sample size and representativeness (Dillman et al. 2009; de Leeuw and Hox, 2011), despite the risk of obtaining different answers to the same question according to the mode (de Leeuw and Hox 2011; Dillman and Christian, 2005). Several articles show that the answers obtained in face-toface surveys are very similar to answers in web surveys, including the number of protest answers, number of zeros, and the obtained WTPs (Nielsen, 2011; Covey et al., 2010, Van der Heide et al. 2008; Windle and Rolfe, 2011).
} 
We obtained 90 completed questionnaires. This small sample size is a rather common limitation of DCE studies targeting farmers, because this population is more difficult to reach than those of regular citizens or consumers ${ }^{11}$ Moreover, pesticide use is a sensitive issue among farmers, and many refuse to be involved in a survey on this topic. This was particularly true for our study, which was conducted during a period of controversy over pesticides in France, just after a polemic documentary diffused to a large television audience, provoking protests by many farmers. The sample size and representativeness are further discussed below.

The questionnaire lasted less than 20 minutes. Respondents' were told that the study was designed by the French Institute for Agricultural Research (INRA) to implement better-tailored public policies ${ }^{12}$ Then, slides were used to briefly explain the issue addressed by our study.

The first part of the questionnaire was dedicated to general questions on the farmer's activities, size of the farm, and use of pesticides, as well as questions that assess the status quo level of each attribute. The details of the four attributes and their implications were presented thoroughly, delivering information in the most objective and neutral way (see Appendix A.1 for examples of the attribute presentation). We provided real-world examples in the survey description to make the choice sets more realistic, and thus, limit the hypothetical bias. A set of qualitative questions was used to assess the respondent's awareness of the interactions between agricultural practices, public policies, and pesticide issues (see Appendix, Table 8).

The eight choice sets were then presented. The order of the choice sets was randomized to avoid having potential declining concentration always affecting the same choice sets (last choices). Respondents had access to the definition of each attribute whenever needed during the choice sequence (accessible using informational icons in the web survey). In order to detect protest answers, those farmers who chose the status quo in all choice sets were asked for additional information about their choices.

After the choice sets, respondents were presented with questions on their socioeconomic situation (income level, gender, age, level of education) and on their understanding of the choice sets.

\footnotetext{
${ }^{11}$ Many published DCEs target farmers with relatively small sample sizes, for example, 128 German farmers in Schulz et al. (2014), 104 Australian farmers in Greiner (2016), 97 English farmers in Beharry-Borg et al. (2013), 49 U.S. farmers in Hudson and Lusk (2004), and 104 French farmers in Jaeck and Lifran (2014).

${ }^{12}$ The information delivered in this introductory part favors consequentiality, that is, the fact that respondents believe there is a nonzero probability that their answers influence actual decisions, and that they may have to pay something as a result. Consequentiality is a necessary (but not sufficient) condition for incentive-compatibility (see Johnston et al., 2017).
} 
Some respondents were removed from the sample, for various reasons: i) 10 were removed because their response times were too short (those responding to the web survey in less than eight minutes were considered unreliable) (see Börger 2016 for an analysis of the link between response time and quality of the answer); and ii) five were removed owing to a lack of understanding or an unwillingness to answer truthfully 13

Tables 2 and 3 present the descriptive statistics for the final sample of 75 farmers, $31 \%$ of whom are women. The respondents' ages range from 23 to 68 years, with an average of 46 years. The mean size of their farms is about 117 hectares.

\begin{tabular}{lccccc}
\hline \hline & Obs & Mean & S.D & Min & Max \\
\hline Age & 75 & 45.67 & 10.60 & 23 & 68 \\
Size of the farm (ha) & 75 & 116.68 & 103.18 & 0.1 & 500 \\
Yearly turnover (€) & 65 & 168113 & 151770 & 1 & 650000 \\
Yearly average profit/ha (€) & 30 & 753.33 & 1398.91 & 10 & 8000 \\
\hline \hline
\end{tabular}

Table 2: Descriptive Statistics

In Table 4, we compare the main sociodemographic characteristics of our sample with the population of French farmers. ${ }^{14}$ Our sample is representative of the population in terms of age, the sex ratio, and the proportion of respondents with high school diplomas. However, there is an over-representation of farmers with higher education diplomas (which is typical for web surveys), and the mean size of farms is significantly larger in our sample than it is for the country as a whole.

Additional descriptive statistics on farm location and type are presented in the Appendix (Table 7). Our sample is not fully representative of the various French administrative regions, with an over-representation of central areas and field crop farmers. This may explain why the mean farm size is larger than the mean value for France. The Appendix also presents statistics on respondents' awareness (Table 8).

\footnotetext{
${ }^{13}$ These were identified by the follow-up question, "Were the explanations and the choice cards clear to you?: Yes/No. If you answered no, please provide further information" (open-ended question).

${ }^{14} \mathrm{~A}$ comparison with nonorganic French farmers only would have been more appropriate, but data were not available for this subpopulation.
} 


\begin{tabular}{|c|c|c|}
\hline & $\mathrm{Nb}$ & $\%$ \\
\hline $\begin{array}{l}\text { Number of farmers having some revenues } \\
\text { from outside }\end{array}$ & 39 & $52,0 \%$ \\
\hline $\begin{array}{l}\text { Number of farmers having suscribed } \\
\text { to a harvest insurance }\end{array}$ & 33 & $44,0 \%$ \\
\hline \multicolumn{3}{|l|}{ Gender } \\
\hline Women & 23 & $30,7 \%$ \\
\hline Men & 52 & $69,3 \%$ \\
\hline \multicolumn{3}{|l|}{ Education } \\
\hline No formal qualifications & 1 & $1,3 \%$ \\
\hline Youth Training/BTEC 1st Diploma & 13 & $17,3 \%$ \\
\hline High School Diploma & 25 & $33,3 \%$ \\
\hline Bachelor & 19 & $25,3 \%$ \\
\hline Master's Degree & 13 & $17,3 \%$ \\
\hline $\mathrm{PhD}$ & 1 & $1,3 \%$ \\
\hline Other & 3 & $4,0 \%$ \\
\hline
\end{tabular}

Table 3: Descriptive Statistics

\begin{tabular}{lcc}
\hline \hline & Our Sample & French farmers \\
\cline { 2 - 3 } Mean age & 45.7 & 50.6 \\
Farm size (hectares) & 117 & 56 \\
Men / women ratio & $69 \%$ of men & $68 \%$ of men \\
Proportion having a high school diploma & $33 \%$ & $21 \%$ \\
Proportion having a higher education diploma & $43.9 \%$ & $17 \%$ \\
\hline \hline
\end{tabular}

Table 4: Comparison of socio-demographic characteristics 


\section{Theoretical foundations of the choice experiment approach and model specifications}

The choice experiment modeling framework relies on the characteristics theory of value (Lancaster, 1966) and the random utility theory (McFadden, 1974). Lancaster (1966) assumes that a good may be defined by a set of characteristics. Therefore, the value of a good is the sum of the values of all its characteristics. Applying this theory in a choice experiment approach means that an alternative can be characterized by a set of characteristics (called attributes in the DCE literature), and that each attribute is associated with a utility level. The (indirect) utility $V_{n, i}$ of an alternative $i \in\{1, \ldots, I\}$ for respondent $n \in\{1, \ldots, N\}$, where $I$ and $N$ are given, possibly large, finite integers, is derived from the $K$ observable attributes of the alternative, denoted by $X_{i}=\left(x_{i 1}, \ldots, x_{i k}, \ldots, x_{i K}\right)$. In addition, it depends on a set of $A$ social, economic, and attitudinal characteristics (socioeconomic variables) that characterize the respondent, denoted by $Z_{n}=\left(z_{n 1}, \ldots, z_{n a}, \ldots, z_{n A}\right)$ :

$$
V_{n, i}=V\left(X_{i}, Z_{n}\right) \quad \text { for } n=1, \ldots, N \text { and } i=1, \ldots, I .
$$

McFadden (1974) proposes that individuals make choices according to a deterministic part, with some degree of randomness. Combining the two theories, we assume that the random utility of alternative $i$ for individual $n, U_{n, i}$, is composed of the deterministic component $V_{n, i}=V\left(X_{i}, Z_{n}\right)$, and a stochastic element, $\epsilon_{n, i}$ :

$$
U_{n, i}=V\left(X_{i}, Z_{n}\right)+\epsilon_{n, i}
$$

where the error term $\epsilon_{n, i}$ is a random variable that captures the unsystematic and unobserved random element of the choice of respondent $n$ (Hanley et al., 2005, Holmes and Adamowicz, 2003; Louviere et al., 2000).

Assuming the rationality of individuals, respondents are supposed to associate each alternative $i$ with a random utility level $U_{n, i}$, and choose the option that provides them with the greatest utility within a given choice set. Therefore, agent $n$ will choose alternative $i$ from a finite set of alternatives $S$ if this random utility is greater than the random utility $U_{n, j}$ of any other alternative $j$ in $S$ :

$$
U_{n, i}>U_{n, j} \Rightarrow V_{n, i}+\epsilon_{n, i}>V_{n, j}+\epsilon_{n, j} \quad \forall j \neq i ; i, j \in S \text {. }
$$

Before estimating an econometric model, we need to specify the deterministic part of the utility function. The linear specification is often chosen in the literature, because it is the simplest to work with. We thus introduce the column vector of coefficients $\beta_{n}=\left(\beta_{n 1}, \ldots, \beta_{n K}\right)^{\prime}$, which are the coefficients quantifying the (linear) 
influence of the $K=4$ attributes on utility and may be specific to each respondent $n$.

We also introduce an alternative-specific constant, which corresponds to the status quo. For this, we define the dummy variable $S Q$, which takes the value one in the status quo alternative, and zero otherwise. Thus, the $S Q$ term defines a situation with no variation in the farmer's profit, no additional years of large production losses, no additional administrative commitments, and no reduction in the impact on health and environment. Hence, a positive and statistically significant coefficient $\eta$ for the $S Q$ dummy variable (see equation 4 below) indicates a preference for not moving from the current situation.

The interactions with the socioeconomic characteristics can be modeled in different ways, for example, by interacting with the status quo or with the attributes. Hence, the model is specified so that the probability of selecting alternative $i$ is a function of the attributes $X_{i}$ of that alternative, of the alternative specific constant for the status quo, and the socioeconomic characteristics $Z_{n}$ of the respondent $n$. Because the utility $V_{n, i}$ is assumed to be an additive function, equation (2) becomes

$$
U_{n, i}=\left(\eta+Z_{n} \alpha^{S Q}\right) S Q+X_{i}\left(\beta_{n}+\alpha Z_{n}^{\prime}\right)+\epsilon_{n, i} .
$$

The column vector of coefficients $\alpha^{S Q}=\left(\alpha_{1}^{S Q}, \ldots, \alpha_{A}^{S Q}\right)^{\prime}$ captures the effect of the socioeconomic characteristics on the status quo utility. The vector $X_{i}=$ $\left(x_{i 1}, x_{i 2}, x_{i 3}, x_{i 4}\right)$ corresponds to the different levels taken by the attributes "Profit," "Production risk," "Administrative commitment," and "Health and environmental impacts," respectively. The matrix $\alpha$ of size $(K, A)$ is composed of coefficients $\alpha_{i, a}$, capturing the cross-effect of socioeconomic characteristic $a$ on attribute $i$. Thus specified, the coefficients $\beta_{n}=\left(\beta_{n 1}, \beta_{n 2}, \beta_{n 3}, \beta_{n 4}\right)^{\prime}$ quantify the influence of the various levels of the four attributes on the utility of respondent $n$, relative to the utility of the status quo option that appeared on every choice card.

Different econometric models, which rely on different assumptions in the distribution of error terms $\epsilon_{n, i}$, can be used to analyze the discrete choice data. Similarly, the attributes $X_{i}=\left(x_{i 1}, x_{i 2}, x_{i 3}, x_{i 4}\right)$ can be treated as discrete or continuous variables, and it is possible to combine qualitative and quantitative attributes in the same model specification.

\section{A Random Parameter Logit model to account for farmers' heterogeneous preferences}

We used a random parameter logit (RPL) model, also called the mixed logit model, to analyze our data. Appendix A.3 presents the advantages of this model with respect to other econometric models we tested: the conditional logit (CL) model, 
and the latent class (LC) model. The RPL model is shown to outperform the CL and LC models, based on the CAIC and BIC criteria.

Table 5 presents the results of the estimation of the RPL model when both the cost attribute ("Profit") and the "Health and environmental impacts" attribute, which have quantitative levels, are specified as continuous variables, and the two other attributes ("Production risk" and "Administrative commitment") are modeled as dummy-coded variables ${ }^{15}$ As commonly assumed in the literature (Hensher and Green, 2003), the coefficient associated with the cost attribute is considered to be constant, whereas the other RPL parameters are assumed to be normally distributed ${ }^{16}$

As explained by Burton (2018), econometric models that include categorical variables (as here) are not invariant to the choice of the "base" category when random parameters are estimated, unless they are allowed to be correlated. When not taken into account, the invariance can lead to significant increases in TypeI errors. To avoid this bias, all results for the RPL models presented here are estimated using a full covariance matrix structure in which the random coefficients are assumed to be correlated.

We considered two versions of the model. The first does not account for socioeconomic variables: the vector $Z_{n}$ is not introduced in equation 4 (left-hand side model in Table 5). The second extends the model by considering interactions with socioeconomic variables (right-hand side model in Table 5p). We first present the results of the model without interactions, and then discuss the effect of the socioeconomic variables.

\subsection{Model without interactions with socioeconomic variables}

In the results of the RPL estimations without interactions with socioeconomic variables, presented in the first two columns of Table 5, the standard deviations of most coefficients are strongly significant, confirming that the RPL model provides a significantly better representation of the choices than the CL model does.

\footnotetext{
${ }^{15}$ These attributes are encoded using $\left.i\right)$ two dummy-coded variables $(+1$ year" and " +2 years") for the "Production risk" attribute and ii) three dummy-coded variables ("Charter", "Contract" and "Certification") for the "Administrative commitment" attribute. Thus defined, the base categories for the attributes, which are tied to the $S Q$, are "no additional years of large production losses" and "no additional administrative commitment," respectively.

${ }^{16}$ The normal distribution is symmetric and unbounded. It has the advantage of not making assumptions of farmers' preferences; both positive and negative parameter values may be taken to capture heterogeneity in the population. On the contrary, not allowing the cost attribute to be a random parameter ensures that all respondents have a positive valuation of profits in their utility, according to intuition.
} 


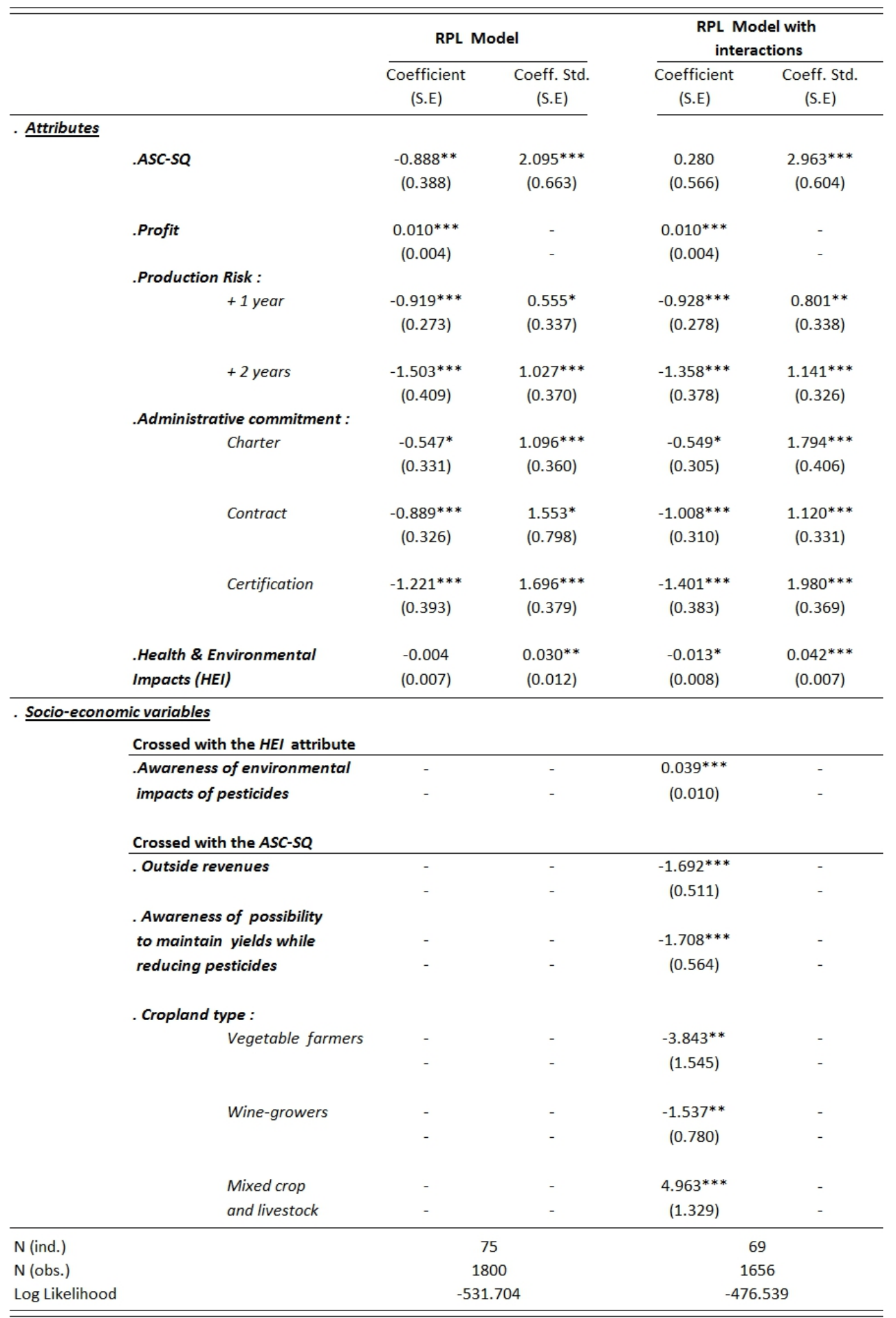

ASC-SQ: Alternative Specific Constant corresponding to the status quo alternative.

*** indicates significance at $1 \%, * *$ at $5 \%$ and $*$ at $10 \%$.

Table 5: Results of RPL models with and without socioeconomic interactions (estimated with a full covariance matrix ptructure in which the random coefficients are assumed to be correlated) 
Owing to the rather small size of our sample, we retain the conservative value of $5 \%$, rather than $10 \%$, as the chosen level of significance (i.e., the probability of committing a Type-I error) to reject (or not) the null hypothesis of the Student tests. All attributes and levels, except for the "Health and environmental impacts" attribute and the "Charter" level of the "Administrative commitment" attribute, are statistically significant at this level. The fact that the "Charter" level is ignored by respondents is not surprising, given that a charter is, in general, weakly constraining compared with other administrative commitments (certification or contracting). The fact that the environmental and health impacts of pesticides do not affect respondents' utility significantly may be intriguing, and is explored further in the next subsection.

With regard to the statistically significant coefficients, the alternative specific constant corresponding to the status quo $A S C-S Q$ is negative: on average, farmers place a negative value on maintaining the status quo. However, its standard deviation is large (2.095), highly significant, and covers positive signs (i.e., some farmers value the status quo positively). The cost attribute coefficient ("Profit") is also strongly significant and, unsurprisingly, its positive sign indicates that a higher profit has a positive effect on respondents' utility.

As expected, the risk of large production losses has a negative effect on utility, and the coefficients of both dummy variables "+1 year" and "+2 years" for "Production risk" are strongly statistically significant. However, these negative effects are very heterogeneous in the sample, as indicated by the large and significant standard deviations for these attributes. If the farmers in our sample are reluctant to face additional risk on production, their aversion to that risk varies from low to high. In addition, the effect of " +2 years" is more negative, on average, than that of "+1 year", which denotes an overall perception of increased risk. However, when computing the $95 \%$ Confidence Interval (CI) of these mean estimated coefficients, we find that the $95 \%$ CI of the " +2 years" category overlaps with that of the "+1 year" category ${ }^{17}$ Thus, there seems to be no scope effect related to our production risk, which may be considered almost qualitatively. We emphasize the implication of this heterogeneity when discussing the WTA associated with the additional production risk in subsection 4.3. Moreover, the interaction between the profit attribute and the production risk attribute is not significant, as it would be if that risk were treated jointly with the outcome, according to expected utility theory. This result suggests a direct distaste of large production losses, rather than

${ }^{17}$ This CI is computed as follows:

where $\hat{\beta}_{i}$ is the (mean) estimated value of the $i$ th attribute's coefficient, $\hat{\sigma}_{\hat{\beta}_{i}}$ is its standard error, and $t_{\alpha}$ corresponds to the critical value for a significant threshold $\alpha(1.96$, in our case). 
standard risk aversion (refer to Glenk and Colombo, 2013).

The dummy variables associated with the "Administrative commitment" attribute, except for "Charter", have significant and negative coefficients. Thus, in general, increased administrative commitments reduce respondents' utility significantly. Interestingly, the administrative frameworks "Contract" and "Certification" represent a burden, rather than a support, for respondents.

\subsection{Role of interactions with socioeconomic variables}

In the extended model (Table 5, two last columns), we test the effect of the socioeconomic variables on the coefficients associated with each attribute and the $A S C-S Q$ variable. Examining such interactions helps us to better understand farmers' preferences toward each attribute. We assume that the effects of the socioeconomic variables are homogeneous over the sample, with constant coefficients, as is common in the literature.

Interactions were tested using the following socioeconomic and attitudinal variables: age, income, level of education, farm size, sources of revenue from outside the farm, farm type, whether the respondent is aware of the environmental and health impacts of pesticide use, whether the respondent trusts in the possibility of maintaining yields while reducing pesticide use, whether the respondent initially knows her/his level of pesticide use, and whether the respondent has subscribed to an insurance contract. We tested the significance of the interaction between these variables and each attribute in an extended model, and identified significant interactions using the backward elimination procedure. All but one of the interactions that remain statistically significant after this procedure are interactions with the status quo (i.e., the $A S C$-SQ variable). These results are useful, because they provide information on which types of respondents (characterized by socioeconomic variables) are more willing to move away from the status quo (i.e., to reduce their use of pesticides). Furthermore, there is one significant interaction between a socioeconomic variable and an attribute: the awareness of the environmental impact of pesticides plays a significant and positive role on the "Health and environmental impacts" attribute (see below) 18

All attribute coefficients in the extended model (top half of the two last columns) are close to those in the model without interaction, showing that the estimations are robust. The "Health and environmental impacts" and "Charter" attributes remain nonsignificant at the $5 \%$ level. However, as already pointed out, the coefficient of the interaction term between the "Health and environmental impacts"

\footnotetext{
18"Awareness of environmental impacts of pesticides" is a dummy variable derived from the qualitative question "Do you think pesticides affect the environment?" The response takes the value one if respondents think the impact is "important" or "very important," and zero otherwise (see Appendix A.2.
} 
attribute and the dummy variable "Awareness of environmental impacts of pesticides" is statistically significant at the $1 \%$ level, and positive. In other words, our results show that respondents who think pesticides affect the environment are significantly and positively motivated by the environmental and health outcome of pesticide reduction, as is consistent with intuition but controversial in the literature (Isin and Yildirim, 2007). This represents about $65.4 \%$ of our sample (see Appendix A.2.

With regard to the influence of other socioeconomic variables (crossed with the $A S C-S Q$ variable), the coefficient of "Outside revenues" is negative and statistically significant at the $1 \%$ level: farmers who obtain some revenue from outside the farm are significantly more willing to change their practices (because they have a stronger disutility from staying in the status quo). We interpret this result jointly with the effect of the production risk: Farmers with an outside, stable income may be less reluctant to adopt pesticide-reducing practices, in spite of the increased risk of large production losses. Farmers who are aware that they can maintain yields while reducing their use of pesticides ("Awareness of possibility maintaining yields, while reducing pesticides") are also significantly more willing to leave the status quo. This confirms the feedback provided by the focus groups and other discussions with farmers that the yield, beyond total profits, is a major decision factor; this pattern is mentioned frequently in the literature (Burton et al., 2008; Pedersen et al. 2012). The cropland types are coded as dummies; their coefficients must be interpreted as differences with respect to field crops farms (i.e., the reference level). The results indicate that vegetable farmers and wine growers are more willing to leave the status quo than are farmers of field crops. Mixed crop/livestock farmers are significantly less willing to change their farming practices than field crops farmers are.

Finally, the $A S C-S Q$ coefficient is nonsignificant in the model with interactions. Thus, in this setting, respondents are indifferent between staying or leaving the status quo, on average. Therefore, the willingness to leave the status quo identified in the model without interactions can be explained fully by the socioeconomic characteristics of respondents. Note that, because respondents are indifferent between changing and maintaining the status quo, our sample does not seem to be biased toward farmers who particularly wish to change their farming practices. This is reassuring, because farmers who agree to answer this survey may be people who are naturally sensitive to the pesticide topic and are more willing to change their practices than is the average farmer. There could be a selection bias due to self-selection (Heckman, 1979), which does not seem to occur in our case. 


\subsection{WTA estimates}

Welfare measures can be determined in the form of marginal WTP/WTA by estimating the marginal rate of substitution (MRS) between the considered attribute and income (Louviere et al., 2000$)$. The marginal utility of income is represented by the cost attribute's coefficient, $\beta_{\text {cost }}$. Because we study the motivation of farmers to reduce their use of pesticides, it is easier to interpret this MRS as a WTA. This is consistent with the fact that most nonmonetary attributes of our choices are valued negatively by respondents.

Because utilities are modeled as linear functions of the attributes, the MRS between two attributes is the ratio between the corresponding coefficients. For attributes modeled as dummy-coded variables, the $W T A_{k}^{l}$ associated with attribute $k$ and category $l$ is $W T A_{k}^{l}=-\frac{\beta_{k}^{l}}{\beta_{\text {cost }}}$. This corresponds to the WTA to move from the status quo category of attribute $k$ to category $l$.

The WTA estimates presented in Table 6 are calculated using the RPL models shown in Table 5. The estimated standard deviations and CIs around the mean of the WTA estimates are obtained using the delta method at a $95 \%$ confidence interval. WTA estimates are similar using the RPL with or without interactions, which shows that our estimates are rather robust; thus, we focus on the RPL with interactions when interpreting the results. No WTA is computed for $i$ ) the "Health and environmental impacts" attribute for respondents thinking pesticides do not impact the environment, and ii) the "Charter" level, because neither coefficient is statistically significant at the $5 \%$ level in the RPL model with interactions.

Farmers in our sample need to receive approximately 90 euro per hectare per year $(€ /$ ha/yr), on average, to accept one additional year out of 10 of the risk of large production losses due to pests.19 In addition, they need to receive 132 $€ /$ ha/yr to accept two additional years of that risk. The production risk attribute is clearly a dominant criterion in our respondents' decisions. Farmers express high preferences for not bearing any additional risk of large production losses, as shown by the high associated WTAs. Furthermore, when considering the mean estimates of both WTAs, this attribute does not seem to be linear, in the sense that farmers need to receive more for the first additional year of risk than they do for the second year ${ }^{20}$ For our respondents, the unique fact of having an increased risk of large production losses, rather than the extent of the risk increase, seems to influence their decisions most.

For "Administrative commitment," all else being equal, farmers need to re-

\footnotetext{
${ }^{19}$ Note that this attribute is measured for a given profit level (the cost attribute) and, thus, only measures the distaste of the additional risk of large production losses.

${ }^{20}$ This nonlinearity in the effect of increased risk of large production losses is even more significant given that the maximum value of the CI of the WTA for the one-year level is higher than the minimum value of the CI for the two-year level.
} 


\begin{tabular}{|c|c|c|}
\hline & RPL Model & $\begin{array}{l}\text { RPL Model with } \\
\text { interactions }\end{array}$ \\
\hline & $\begin{array}{l}\text { Mean } \\
(95 \% \mathrm{Cl})\end{array}$ & $\begin{array}{c}\text { Mean } \\
(95 \% \mathrm{Cl})\end{array}$ \\
\hline \multicolumn{3}{|l|}{ Attributes } \\
\hline \multicolumn{3}{|l|}{.Production Risk: } \\
\hline \multirow[t]{2}{*}{+1 year } & 96.84 & 90.25 \\
\hline & {$[32.10 ; 161.58]$} & {$[32.72 ; 147.78]$} \\
\hline \multirow[t]{2}{*}{+2 years } & 158.46 & 132.14 \\
\hline & {$[74.33 ; 242.59]$} & {$[68.74 ; 195.53]$} \\
\hline \multicolumn{3}{|c|}{ Administrative commitment : } \\
\hline Charter & - & - \\
\hline \multirow[t]{2}{*}{ Contract } & 93.67 & 98.08 \\
\hline & {$[13.34 ; 174.00]$} & {$[22.26 ; 173.90]$} \\
\hline \multirow[t]{2}{*}{ Certification } & 128.71 & 136.29 \\
\hline & {$[35.74 ; 221.68]$} & {$[46.28 ; 226.31]$} \\
\hline \multirow{2}{*}{$\begin{array}{l}\text {.Health \& Environmental } \\
\text { Impacts (HEI) }\end{array}$} & - & - \\
\hline & & \\
\hline \multicolumn{2}{|c|}{ for respondent thinking pesticides do not impact the environment } & - \\
\hline \multirow{2}{*}{\multicolumn{2}{|c|}{ for respondent thinking pesticides impact the environment }} & -3.75 \\
\hline & & {$[-7.08 ;-0.42]$} \\
\hline
\end{tabular}

Table 6: WTA estimates for the Random Parameter Logit models 
ceive, on average, $98 € / \mathrm{ha} / \mathrm{yr}$ to sign agri-environmental contracts with public authorities, and $136 € / \mathrm{ha} /$ yr to commit to a certification. The WTA for a charter commitment is not significant at the 5\% level. Unsurprisingly, respondents need to receive more to enter a certification process than an agri-environmental contract, which itself requires more compensation than a charter. This is intuitive, because a certification includes rigorous specifications and controls, whereas a charter is very weakly constraining. Signing an agri-environmental contract with public authorities, such as an Agri-Environmental Scheme, usually implies controls and specifications that are less constraining than a certification associated with a label. See, for instance, Sutherland (2011) on the difficulties of adopting a certification, with an example of English farmers and the organic label.

Respondents who believe that pesticides affect the environment $(65.4 \%$ of the sample) are significantly willing to pay almost $4 € /$ ha/yr to reduce by $1 \%$ the impacts of pesticides on health and environment. In contrast, those who do not believe that pesticides impact the environment are, on average, not willing to pay for health and environment improvements.

\section{Conclusion and policy implications}

Our study investigates farmers' motivations and obstacles related to reducing their use of pesticides. We use a quantitative approach based on a discrete choice experiment to measure the relative weight of various factors that influence farmers' decisions. We value farmers' WTA for several nonmarket components of their decisions, such as the administrative framework of a practice change, the resulting reduction of the impact of pesticides on health and the environment, and the additional risk of large production losses. For the latter attribute, because farmers use pesticide as an insurance device to limit production losses, without necessarily increasing the total mean income (Menapace et al., 2013; Pedersen et al., 2012), we expected this risk would be a major component explaining farmers' reluctance to reduce pesticides, something barely examined by the quantitative literature on this topic.

We find that most respondents in our sample do not consider the administrative framework that may accompany changes in agricultural practices as an opportunity for support or integration in a network, but rather as a burden. In particular, on average, Agri-Environmental Schemes taking the form of a contract with public authorities are valued negatively, which is consistent with the literature (Ruto and Garrod, 2009, Christensen et al., 2011). All else being equal, farmers in our sample would need to receive, on average, $98 € /$ ha/year to sign such a contract. In addition, on average, the farmers in our sample would need to receive 136 $€ /$ ha/year to join a certification on pesticide reduction. 
With regard to the effect on production risk, our results show that farmers dislike increased risk of large production losses, regardless of the effect of the practice change on the level of mean profit. We can relate this result to the fact that the yield is an objective per se for many farmers. The risk of a large production loss due to pests is a prominent obstacle to the reduction in the use of pesticides. All else being equal, farmers in our sample need to receive on average $90 € /$ ha/year to accept one additional year, over 10 years, of large production losses due to pests. This amount is not very much higher for two additional years (132€/ha/year), showing that they perceive this risk more qualitatively than quantitatively. According to these results, our respondents tend to experience a psychological cost from the risk of large production losses, independently of the financial outcome.

The impact of agricultural practices on the environment and human health plays a subtle role in the decisions of our respondents. At first glance, this attribute does not seem to be decisive for the interviewed population. However, when taking into account respondents' awareness of the environmental impacts of pesticides, we understand this behavior better. Respondents who believe that pesticides affect the environment (about $65 \%$ of the sample) are significantly willing to pay to reduce pesticide impacts. They are, for example, willing to pay $75 €$ /ha/year to reduce the health and environmental impacts of pesticides by $20 \%$.

Two other results are worth mentioning. First, it seems that the existence of outside revenue is a determining factor in farmers' willingness to change practices. Farmers with low, insecure incomes may be locked into pesticide intensive practices, and lump-sum subsidies that are independent of farming activities could help them to adopt riskier low-pesticide practices. Second, respondents who believe that yields cannot be maintained while reducing pesticides seem reluctant to change their practices. Thus, it is necessary to increase informational campaigns on alternative farming practices that, in some cases, do allow to maintain satisfactory yields and reduce pesticides (as demonstrated by Lechenet et al., 2017, among others). Education campaigns on farm accounting and composition of profit could also help farmers understand that aiming at a high yield can be a misleading objective.

Our results shed some light on suitable agri-environmental policies. Sufficiently high payments are required to compensate for a reduction in the use of pesticides, for three main reasons. Farmers may need i) significant incentives to overcome their distaste of the increased risk of large production losses ("production-risk premium"), and ii) an "administrative burden premium" to accept changing their current practices, whereas iii) environmental and health improvements may not be a sufficient motivation for some farmers. In addition, the high heterogeneity of preferences observed in our sample favors differentiated payments by farmer 
type, when possible. Measures should be taken to reduce these necessary premiums. With regard to production risk, the Income Stabilization Tools (IST) discussed within the European Common Agricultural Policy or the Agricultural Risk Coverage (ARC) proposed within the Farm Bill 2014 in the United States could be useful. In addition, ensuring farmers have access to reliable and affordable production-risk insurance is advised.With regard to the administrative burden, simplified formalities are necessary. Dedicated studies would be useful to understand which administrative tasks trouble farmers the most. Free and easily accessible assistance for these tasks should also be generalized.

Because outside revenues favor adoption, area-based payments (as the direct payments in the successive Farm Bills in the United States or in Pillar 1 of the European Common Agricultural Policy), which are independent of production levels, could increase sure income. They could be conditional on pesticide reduction and even be combined with additional payments for those who go beyond legal requirements. In addition, contrary to the recent guidance tendency, result-based payments (e.g., conditional on biodiversity indicators) could be less favorable to pesticide reduction than management-based payments that are more certain. A remuneration of low-pesticide practices through the market via higher prices is less satisfying than the above mentioned direct payments on this point, because it is correlated to the production level.

Our study has several limitations. Our sample, although representative on several criteria, is rather small and over-representative of large farms from the center of France. As discussed previously, a small sample size is a common drawback in the DCE literature targeting farmers, especially when treating such sensitive issues as pesticide reduction. To overcome this limit, we limited blocking to two blocks in our experimental design, inducing a reasonable number of respondents per block, as explained in Section 2.2. In addition, according to Greiner (2016), using a D-efficient experimental design, as we do, requires a much smaller sample size than a random orthogonal design. As stated by this author, "a systematic review of discrete choice experiments based on design features and sample size by Bliemer and Rose (2011) and Rose and Bliemer (2013) supports the assertion." Our results should, however, be interpreted with caution, and are not necessarily directly applicable to the whole population of French farmers.

Further research is needed to understand the drivers of the adoption of practices that reduce pesticide use. In particular, our work is a first attempt to measure the role of production risk in farmers' behavior. Other studies of this type would be useful to confirm, reject, or refine the obtained values using other samples. As mentioned in Chevassus-au Louis et al. (2009), the accumulation of many small local studies, yielding a database of monetary values, is needed to support public decision-making. Moreover, complementary choice experiments among farmers 
could help us to understand the relative weight of other factors, such as the need for technical training on new practices, role of network and neighborhood connections, and the impact of a practice change on farmers' work schedule. 


\section{References}

Adamowicz, V. and Boxall, P. (2001). Future directions of stated choice methods for environment valuation. Choice experiments: A new approach to environmental valuation, London, pages 1-6.

AgenceBio (2017). La bio change d'échelle en préservant les fondamentaux. BioBaromètre 2017, Dossier de presse.

Baerenklau, K. (2005). Toward an understanding of technology adoption: Risk, learning, and neighborhood effects. Land Economics, 81(1):1-19.

Bech, M., Kjaer, T., and Lauridsen, J. (2011). Does the number of choice sets matter? results from a web survey applying a discrete choice experiment. Health Economics, 20(3):273-286.

Beharry-Borg, N., Smart, J., Termansen, M., and Hubacek, K. (2013). Evaluating farmers' likely participation in a payment programme for water quality protection in the UK uplands. Regional Environmental Change, 13:633-647.

Bernard, J. C. and Bernard, D. J. (2010). Comparing parts with the whole: willingness to pay for pesticide-free, non-gm, and organic potatoes and sweet corn. Journal of Agricultural and Resource Economics, pages 457-475.

Birol, E., Smale, M., and Gyovaii, A. (2006). Using a choice experiment to estimate farmers' valuation of agrobiodiversity on Hungarian small farms. Environmental and Resource Economics, 34:439-469.

Blazy, J., Carpentier, A., and Thomas, A. (2011). The willingness to adopt agroecological innovations: Application of choice modelling to Caribbean banana planters. Ecological Economics, 72:140 - 150.

Bliemer, M. and Rose, J. (2010). Serial Choice Conjoint Analysis for Estimating Discrete Choice Models. in Stephane Hess , Andrew Daly (ed.) Choice Modelling: The State-of-the-art and The State-of-practice, pages 137-161.

Bliemer, M. and Rose, J. (2011). Experimental design influences on stated choice outputs: An empirical study in air travel choice. Transportation Research Part A: Policy and Practice, 45(1):63 - 79.

Börger, T. (2016). Are fast responses more random? testing the effect of response time on scale in an online choice experiment. Environmental and Resource Economics, 65(2):389-413. 
Bourguet, D. and Guillemaud, T. (2016). The hidden and external costs of pesticide use. Sustainable Agriculture Reviews, 19:35-120.

Broch, S. W. and Vedel, S. E. (2012). Using choice experiments to investigate the policy relevance of heterogeneity in farmer agri-environmental contract preferences. Environmental and Resource Economics, 51:561-581.

Burton, M. (2018). Model invariance when estimating random parameters with categorical variables. Working Paper, 1804.

Burton, R. J., Kuczera, C., and Schwarz, G. (2008). Exploring farmers' cultural resistance to voluntary agri-environmental schemes. Sociologia ruralis, 48(1):1637.

Chevassus-au Louis, B., Salles, J.-M., Pujol, J.-L., Bielsa, S., Martin, G., and Richard, D. (2009). Approche économique de la biodiversité et des services liés aux écosystèmes: contribution à la décision publique, volume 18. Ministère de l'Alimentation, de l'Agriculture et de la Pêche.

Christensen, T., Pedersen, A. B., Nielsen, H. O., Mørkbakand, M., Hasler, B., and S.Denver (2011). Determinants of farmers' willingness to participate in subsidy schemes for pesticide-free buffer zones - A choice experiment study. Ecological Economics, 70 .

Covey, J., Robinson, A., Jones-Lee, M., and Loomes, G. (2010). Responsibility, scale and the valuation of rail safety. Journal of Risk and Uncertainty, 40:85-108.

de Leeuw, E. and Hox, J. (2011). Internet surveys as part of a mixed mode design. In Das, M., Ester, P., and Kaczmirek, L., editors, Social and behavioral research and the Internet: Advances in applied methods and new research strategies. Routledge, Taylor and Francis Group, New York.

Dillman, D. A. and Christian, L. (2005). Survey mode as a source of instability in responses across surveys. Field Methods, 17:30 - 51.

Dillman, D. A., Phelps, G., Tortora, R., Swift, K., Kohrell, J., Berck, J., and Messer, B. L. (2009). Response rate and measurement differences in mixedmode surveys using mail, telephone, interactive voice response (ivr) and the internet. Social Science Research, 38(1):1 - 18.

Dumont, A. M., Vanloqueren, G., Stassart, P. M., and Baret, P. V. (2016). Clarifying the socioeconomic dimensions of agroecology: between principles and practices. Agroecology and Sustainable Food Systems, 40(1):24-47. 
Ecophyto (2015). Note de suivi ecophyto: Tendance du recours aux produits phytopharmaceutiques de 2009 à 2014. Ministère de l'Agriculture, de l'Alimentation et de la Forêt.

Espinosa-Goded, M., Barreiro-Hurlé, J., and Ruto, E. (2010). What do farmers want from agri-environmental scheme design? A choice experiment approach. Journal of Agricultural Economics, 61(2).

Glenk, K. and Colombo, S. (2013). Modelling outcome-related risk in choice experiments. Australian Journal of Agricultural and Resource Economics, 57(4):559 578.

Greiner, R. (2016). Factors influencing farmers' participation in contractual biodiversity conservation: a choice experiment with northern australian pastoralists. Australian Journal of Agricultural and Resource Economics, 60(1):1-21.

Greiner, R., Bliemer, M., and Ballweg, J. (2014). Design considerations of a choice experiment to estimate likely participation by north australian pastoralists in contractual biodiversity conservation. Journal of Choice Modelling, 10:34 - 45 .

Greiner, R., Patterson, L., and Miller, O. (2009). Motivations, risk perceptions and adoption of conservation practices by farmers. Agricultural systems, 99(23):86-104.

Hanley, N., Adamowicz, W., and Wright, R. E. (2005). Price vector effects in choice experiments: an empirical test. Resource and Energy Economics, 27.

Hanley, N., Wright, R., and Koop, G. (2002). Modelling recreation demand using choice experiments: Climbing in scotland. Environmental and Resource Economics, 22(3):449-466.

Hausman, J. and McFadden, D. (1984). Specification tests for the multinomial logit model. Econometrica, 52 .

Heckman, J. J. (1979). Sample selection bias as a specification error. Econometrica: Journal of the econometric society, pages 153-161.

Hensher, D. A. and Green, W. (2003). The mixed logit model: the state of practice. Transportation, 30(2).

Holmes, T. and Adamowicz, W. (2003). Feature based methods. In Champ, P. A., Boyle, K. J., and Brown, T. C., editors, A primer on nonmarket valuation. Kluwer Academic Publishers. 
Horowitz, J. and Lichtenberg, E. (1994). Risk-reducing and risk-increasing effects of pesticides. Journal of Agricultural Economics, 45(1):82-89.

Hoyos, D. (2010). The state of the art of environmental valuation with discrete choice experiments. Ecological Economics, 69(8):1595-1603.

Hudson, D. and Lusk, J. (2004). Risk and transaction cost in contracting: results from a choice-based experiment. Journal of Agricultural \& Food Industrial Organization, 2(1).

Isin, S. and Yildirim, I. (2007). Fruit-growers' perceptions on the harmful effects of pesticides and their reflection on practices: The case of kemalpasa, turkey. Crop protection, 26(7):917-922.

Jaeck, M. and Lifran, R. (2014). Farmers' preferences for production practices: a choice experiment study in the Rhone river delta. Journal of Agricultural Economics, 65(1):112-130.

Johnston, R., Boyle, K., Adamowicz, W., Bennett, J., Brouwer, R., Cameron, T., Hanemann, M., Hanley, N., Ryan, M., Scarpa, R., Tourangeau, R., and Vossler, C. (2017). Contemporary guidance for stated preference studies. Journal of the Association of Environmental and Resource Economists, 4(2):319-405.

Juraske, R., Antón, A., Castells, F., and Huijbregts, M. A. (2007). Pestscreen: A screening approach for scoring and ranking pesticides by their environmental and toxicological concern. Environment international, 33(7):886-893.

Just, R. and Pope, R. (2003). Agricultural risk analysis: Adequacy of models, data, and issues. American Journal of Agricultural Economics, 85(5):1249-1256.

Knowler, D. and Bradshaw, B. (2007). Farmers' adoption of conservation agriculture: A review and synthesis of recent research. Food Policy, 32(1):25 - 48.

Kontoleon, A. and Yabe, M. (2003). Assessing the impacts of alternative 'optout' formats in choice experiment studies: consumer preferences for genetically modified content and production information in food. Journal of Agricultural policy and Resources, 5(1):1-43.

Kuhfuss, L., Preget, R., and Thoyer, S. (2014). Individual preferences and collective incentives: what design for agri-environmental contracts? The case of wine-growers' herbicide use reduction. Review of Agricultural and Environmental Studies, 951(1):111-143. 
Kuhfuss, L., Préget, R., Thoyer, S., and Hanley, N. (2016). Nudging farmers to enrol land into agri-environmental schemes: the role of a collective bonus. European Review of Agricultural Economics, 43(4):609-636.

Lancaster, K. (1966). A new approach to consumer theory. Journal of Political Economy, 74(2).

Lechenet, M., Dessaint, F., Py, G., Makowski, D., and Munier-Jolain, N. (2017). Reducing pesticide use while preserving crop productivity and profitability on arable farms. Nature Plants, 3:170 08.

Liu, E. and Huang, J. (2013). Risk preferences and pesticide use by cotton farmers in china. Journal of Development Economics, 103:202 - 215.

Louviere, J., Hensher, D., and Swait, J. (2000). Stated choice methods : analysis and applications. Cambridge University Press.

Malawska, A. and Topping, C. J. (2016). Evaluating the role of behavioral factors and practical constraints in the performance of an agent-based model of farmer decision making. Agricultural Systems, 143:136 - 146.

Malawska, A., Topping, C. J., and Ørsted Nielsen, H. (2014). Why do we need to integrate farmer decision making and wildlife models for policy evaluation? Land Use Policy, 38:732 - 740.

McFadden, D. (1974). Conditional logit analysis of qualitative choice behaviour. In Zarembka, P., editor, Frontiers of econometrics. Academic press, New York.

Menapace, L., Colson, G., and Raffaelli, R. (2013). Risk aversion, subjective beliefs, and farmer risk management strategies. American Journal of Agricultural Economics, 95(2):384-389.

Nielsen, J. (2011). Use of the internet for willingness-to-pay surveys. a comparison of faceto-face and web-based interviews. Resource and Energy Economics, 33(1):119-129.

Pedersen, A. B., Nielsen, H. Ø., Christensen, T., and Hasler, B. (2012). Optimising the effect of policy instruments: a study of farmers' decision rationales and how they match the incentives in danish pesticide policy. Journal of environmental planning and management, 55(8):1094-1110.

Peterson, J., Smith, C., Leatherman, J., Hendricks, N., and Fox, J. (2015). Transaction costs in payment for environmental service contracts. Amercian Journal of Agricultural Economics, 97(1):219-238. 
Roberts, D., Boyer, T., and Lusk, L. (2008). Preferences for environmental quality under uncertainty. Ecological Economics, 66(4):584 - 593.

Rolfe, J. and Windle, J. (2015). Do respondents adjust their expected utility in the presence of an outcome certainty attribute in a choice experiment? Environmental and Resource Economics, 60(1):125-142.

Roosen, J. and Hennessy, D. (2003). Tests for the role of risk aversion on input use. American Journal of Agricultural Economics, 85(1):30-43.

Rose, J. and Bliemer, M. (2013). Sample size requirements for stated choice experiments. Transportation, 40(5):1021-1041.

Rousset, S., Zervo, B., and Mahé, T. (2012). Analyse socio-économique des politiques phytosanitaires : enjeux et applications. Analyse - Centre d'Etude et Prospective, numéro 45:mai 2012.

Ruto, E. and Garrod, G. (2009). Investigating farmers' preferences for the design of agri-environmental schemes: a choice experiment approach. Journal of Environmental Planning and Management, 52(5).

Schulz, N., Breustedt, G., and Latacz-Lohmann, U. (2014). Assessing farmers' willingness to accept "greening": insights from a discrete choice experiment in germany. Journal of Agricultural Economics, 65(1):26-48.

Skevas, T. and Lansink, A. (2014). Reducing pesticide use and pesticide impact by productivity growth: the case of dutch arable farming. Journal of Agricultural Economics, 65(1):191-211.

Solomon, B. D. (2015). Environmental reviews and case studies: Socioeconomic analysis options for pesticides management in developing countries: A review. Environmental Practice, 17(1):57-68.

Street, D. J., Burgess, L., and Louviere, J. J. (2005). Quick and easy choice sets: constructing optimal and nearly optimal stated choice experiments. International Journal of Research in Marketing, 22:459-70.

Sutherland, L.-A. (2011). "effectively organic": Environmental gains on conventional farms through the market? Land Use Policy, 28(4):815-824.

Thoyer, S., Préget, R., Kuhfuss, L., Le Coënt, P., Gautier-Pelissier, F., Subervie, J., Ibanez, L., Désolé, M., and Tidball, M. (2015). Coud'pouce comportement et usage des pesticides: pour des contrats environnementaux innovants. Programme Evaluation et réduction des risques liés à l'utilisation des Pesticides - Rapport 
Final, (APR 2011 Changer les pratiques agricoles pour préserver les services écosystémiques).

Van der Heide, C. M., Van den Bergh, J. C., Van Ierland, E. C., and Nunes, P. (2008). Economic valuation of habitat defragmentation: A study of the veluwe, the netherlands. Ecological Economics, 67(2):205-216.

Vidogbena, F., Adegbidi, A., Tossou, R., Assogba-Komlan, F., Ngouajio, M., Martin, T., Simon, S., Parrot, L., and Zander, K. (2015). Control of vegetable pests in Benin - Farmers' preferences for eco-friendly nets as an alternative to insecticides. Journal of Environmental Management, 147:95-107.

Wilson, C. and Tisdell, C. (2001). Why farmers continue to use pesticides despite environmental, health and sustainability costs. Ecological Economics, 39:449462.

Windle, J. and Rolfe, J. (2011). Comparing responses from internet and paperbased collection methods in more complex stated preference environmental valuation surveys. Economic Analysis and Policy, 41(1):83-97. 
${ }_{899}$ A Appendix

900

901

\section{A.1 Descriptive sheets of attributes presented to respon- dents}

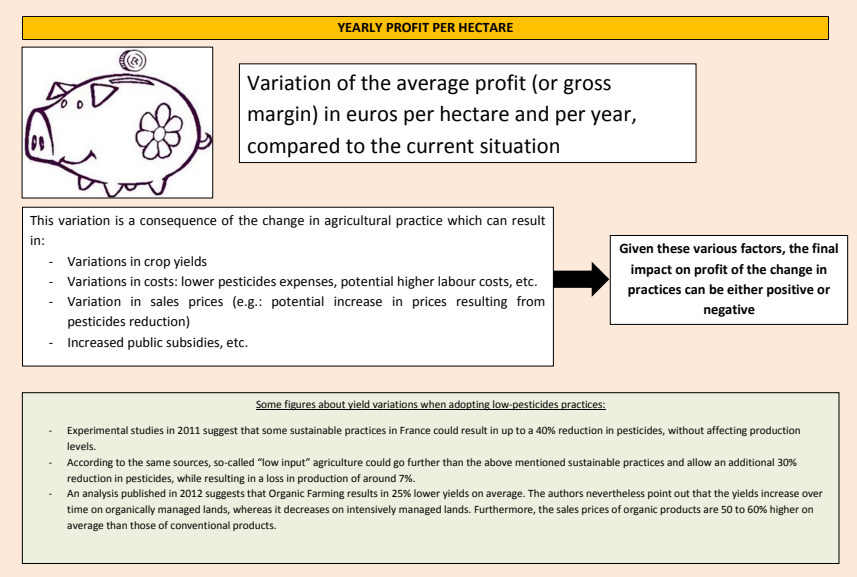

Figure 2: Description of the profit attribute

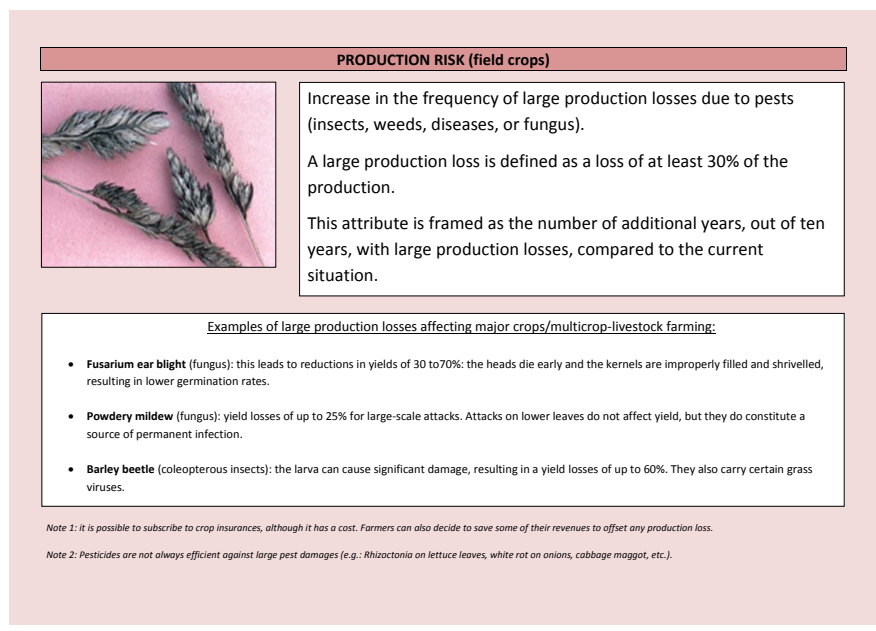

Figure 3: Description of the production risk attribute (field-crops version). There were other versions adapted to various farming activities. 


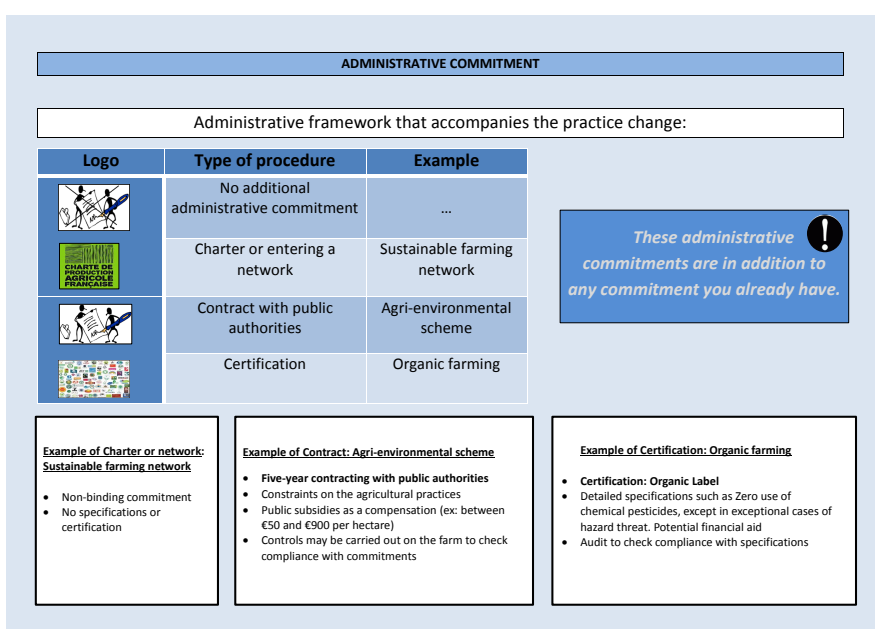

Figure 4: Description of the administrative framework attribute

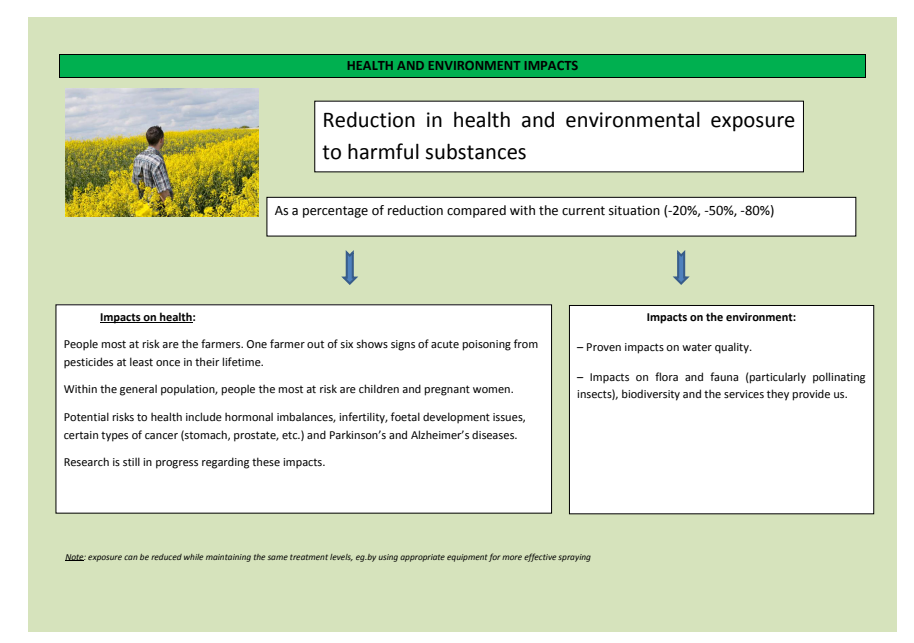

Figure 5: Description of the health and environmental impacts attribute 
902 A.2 Additional descriptive statistics and results of qualitative questions

\begin{tabular}{lccc}
\hline \hline & \multicolumn{2}{c}{ Our Sample } & \multirow{2}{*}{ French farmers } \\
\cline { 2 - 4 } French Region & 7 & $9 \%$ & $9 \%$ \\
Auvergne-Rhöne-Alpes & 7 & $9 \%$ & $6 \%$ \\
Bourgogne-Franche-Comté & 3 & $4 \%$ & $4 \%$ \\
Bretagne & 17 & $23 \%$ & $8 \%$ \\
Centre-Val de Loire & 9 & $12 \%$ & $9 \%$ \\
Grand Est & 2 & $3 \%$ & $9 \%$ \\
Hauts-de-France & 16 & $21 \%$ & $2 \%$ \\
île-de-France & 1 & $1 \%$ & $5 \%$ \\
Normandie & 4 & $5 \%$ & $19 \%$ \\
Nouvelle-Aquitaine & 3 & $4 \%$ & $19 \%$ \\
Occitanie & 5 & $7 \%$ & $4 \%$ \\
Pays de la Loire & 1 & $1 \%$ & $5 \%$ \\
Provence-Alpes-Côte d'Azur & & & \\
& & & - \\
Field crops & 59 & $79 \%$ & - \\
Market gardening & 5 & $7 \%$ & - \\
Wine-growers & 7 & $9 \%$ & - \\
Mixed crop and livestock & 4 & $5 \%$ & \\
\hline Cropland type & & & \\
\hline \hline
\end{tabular}

Table 7: Descriptive Statistics 


\begin{tabular}{|c|c|c|}
\hline & $\mathrm{Nb}$ & $\%$ \\
\hline \multicolumn{3}{|l|}{ Do you see agri-environmental shemes as a constraint? } \\
\hline Yes & 57 & $76,0 \%$ \\
\hline No & 18 & $24,0 \%$ \\
\hline \multicolumn{3}{|c|}{ Do you think reduced pesticides is compatible with constant yields? } \\
\hline Yes & 30 & $40,0 \%$ \\
\hline No & 39 & $52,0 \%$ \\
\hline I don't & 6 & $8,0 \%$ \\
\hline know & 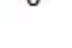 & \\
\hline \multicolumn{3}{|l|}{ Do you think pesticides impact health? } \\
\hline Not at all & 5 & $6,7 \%$ \\
\hline A little & 17 & $22,7 \%$ \\
\hline Significantly & 33 & $44,0 \%$ \\
\hline Very significantly & 15 & $20,0 \%$ \\
\hline I don't know & 5 & $6,7 \%$ \\
\hline \multicolumn{3}{|l|}{ Do you think pesticides impact the environment? } \\
\hline Not at all & 2 & $2,7 \%$ \\
\hline A little & 23 & $30,7 \%$ \\
\hline Significantly & 32 & $42,7 \%$ \\
\hline Very significantly & 17 & $22,7 \%$ \\
\hline I don't know & 1 & $1,3 \%$ \\
\hline
\end{tabular}

Table 8: Sensitivity to administrative commitment and to health and environmental exposure 


\section{A.3 (Not for publication, or For online publication only) Comparing the RPL model with the CL and the LC models}

Different discrete choice models are obtained from various assumptions on the distribution of the random terms. We tested three types of models: conditional logit (CL), random parameter logit (RPL), and latent class (LC). The RPL, which we retained as the more suitable formulation, is presented in the main text. This appendix presents the CL and LC models, and discusses why we chose an RPL model.

We run CL estimations with the same specifications as those in our RPL model, where (the "profit" and "health and environmental impacts" attributes are specified as continuous variables, and the "production risk" and "administrative commitment" attributes are modeled as effect-coded dummy variables), with and without interactions with socioeconomic variables. Although the estimates are similar in their order of magnitude, in both cases, the RPL models are preferable to the CL models, owing to the higher values of their log-likelihood functions, and because the standard deviations in the RPL model are highly significant. We also performed the test proposed by Hausman and McFadden (1984) to test the IIA assumption. If this property is rejected, then the CL model is not appropriate. The results of this test for both CL models, with and without interactions with socioeconomic variables, are presented in Table 9 .

\begin{tabular}{|c|c|c|c|c|c|c|}
\hline \multirow[b]{2}{*}{ Alternative dropped } & \multicolumn{3}{|c|}{ CL model without interactions } & \multicolumn{3}{|c|}{ CL model with interactions } \\
\hline & Chi2 & D.o.f. & P-Value & Chi2 & D.o.f. & P-Value \\
\hline Practice $A$ & 8.50 & 8 & 0.3866 & 15.53 & 13 & 0.2756 \\
\hline Practice B & 10.10 & 8 & 0.2580 & 11.40 & 13 & 0.5771 \\
\hline Practice C (status quo) & 19.20 & 8 & 0.0138 & 37.78 & 13 & 0.0003 \\
\hline
\end{tabular}

D.o.f. : Degrees of freedom of the Hausman and McFadden (1984) test for the IIA property.

NB: The statistic of this test follows a Chi-squared distribution. Chi2 corresponds to the Chi-squared value of this test.

Table 9: Test of independence of irrelevant alternatives (IIA)

The null hypothesis of the Hausman test stipulates that there is no significant difference between the full model and a model with one alternative less. According to Table 9, the Hausman tests lead to the result that the null hypothesis must be rejected at the $5 \%$ and the $1 \%$ levels for the CL models, without and with interactions, respectively, when the alternative status quo is dropped. Because both CL models violate the IIA property, they are not suitable for modeling farmers' preferences belonging to this sample. 
Another way to take the heterogeneity in respondents' preferences into account would have been to analyze the sample using a latent class (LC) model. In this model, respondents are sorted into classes $C$, in which preferences are assumed to be homogeneous in their attributes. In contrast, preferences are allowed to be heterogeneous between classes, thus partitioning the population. Table 10 shows that, regardless of the number of classes considered, the RPL model outperforms the LC model in terms of the Bayesian information criterion $(B I C)$ and the consistent Akaike information criterion $(C A I C)$, because models with lower CAIC and $B I C$ measures are preferable to models with higher measures.

\begin{tabular}{c|ccccc}
\hline \hline $\begin{array}{c}\text { Number of } \\
\text { classes }\end{array}$ & $\begin{array}{c}\text { Parameters } \\
(\mathrm{P})\end{array}$ & $\begin{array}{c}\text { Log } \\
\text { likelihood }\end{array}$ & AIC & CAIC & BIC \\
\hline$-($ RPL) & 15 & -540.19 & 1110.38 & 1160.14 & 1145.14 \\
2 & 17 & -563.62 & 1161.24 & 1217.64 & 1200.64 \\
3 & 26 & -553.72 & 1159.44 & 1245.70 & 1219.70 \\
4 & 35 & -523.07 & 1116.13 & 1232.25 & 1197.25 \\
5 & 44 & -510.51 & 1109.03 & 1255.00 & 1211.00 \\
\hline \hline
\end{tabular}

. AIC (Akaike Information Criterion) $=-2 \mathrm{LL}+2 \mathrm{P}$

. CAIC (Consistent Akaike Information Criterion) $=-2 \mathrm{LL}+\mathrm{P}[(\ln N)+1]$

. BIC (Bayesian Information Criterion) $=-2 \mathrm{LL}+\mathrm{P}[\ln (\mathrm{N})]$

Table 10: Criteria for comparing RPL and LC models 